\title{
Emergency Remote Teaching amid the Covid 19 and the Sources of Stress for EFL Students: A Qualitative Study
}

\author{
Fateme Chahkandi \\ Assistant Professor of Applied Linguistics, Department of English Language, University of Birjand, Birjand, Iran \\ $\square$ Corresponding Author: Fateme Chahkandi, E-mail: f.chahkandi@birjand.ac.ir
}

\begin{abstract}
ARTICLE INFORMATION ABSTRACT
Received: 08 October 2021

Accepted: 07 November 2021

Published: 21 November 2021

DOI: 10.32996/ijels.2021.3.11.5

\section{KEYWORDS}

EFL students, Emergency remote teaching, Emotion diary, Sources of stress

This study intended to identify the sources of stress for EFL students in their transition to emergency remote teaching amid the Covid-19 pandemic. Drawing on the genealogy of emotions and Braun and Clarke's (2006) thematic analysis method, this qualitative study analyzed interview transcripts and emotion diaries gleaned from students over an academic semester. The findings pointed to 4 categories of stressors including academic-related stressors associated with online exams, students' English competency, instructional demands, and excessive workload, and teaching quality. The category of stressors including psychological issues concerned students' low selfconcept and efficacy beliefs, students comparing themselves to others, their learning styles, and social interactions and expectations. Life-related stressors encompassed students' concerns about future life, work-life balance, health and safety at the time of the global pandemic, and distractions and multitasking while students were in class. Finally, technical problems and students' technological skills were recognized as the last source of stress. The findings were then discussed in the light of unique sources of stress attributed to the digital nature of remote learning and the need for a broader conceptualization of students' proficiency in e-learning contexts. Finally, the study concluded with empirical implications for teachers, policymakers, health providers, and counselors.
\end{abstract}

\section{Introduction}

A multitude of studies has explored students' experience of online learning amid the Corona pandemic (e.g. Amzalag, Shapira, \& Dolev, 2021; Raza, Qazi, Khan, \& Salam, 2021). Yet, students' perception of stress and its antecedents has been given scant attention. Research into students' stress in the web-based environment is particularly of significance considering the peculiarities of emergency remote teaching (ERT) under the conditions of the Covid-19 outbreak. Emergency remote teaching has been construed as "a temporary shift of instructional delivery to an alternate delivery mode due to crisis circumstances" (Hodges, Moore, Lockee, Trust, \& Bond 2020, p. 6). As such, ERT is identified as an emergent obligatory response to a global crisis not students' preferred mode of learning. Moreover, not all students have the means, conditions, and technical requirements to embark on online education. Situational and environmental challenges, online educational obstacles, and emotional hurdles such as concerns about mental and physical health have been some of the problems that impact the utility and usefulness of online teaching at the time of pandemic (Aguilera-Hermida, 2020).

Lederer, Hoban, Lipson, Zhou, and Eisenberg (2021) refer to housing and food insecurity, financial problems, lack of social connectedness and isolation, uncertainty about future life, and internet access and technology issues as unique mental health risk factors affecting college students' academic performance and wellbeing during the Covid-19 pandemic. Likewise, Bozkurt and Sharma (2020) point to students' trauma, stress, and psychological pressure at the time of the Corona crisis and ask for a pedagogy of care based on the emotional presence and creating a climate of empathy and care rather than teaching educational content on purely didactic and insensitive grounds.

Copyright: (C) 2021 the Author(s). This article is an open access article distributed under the terms and conditions of the Creative Commons Attribution (CC-BY) 4.0 license (https://creativecommons.org/licenses/by/4.0/). Published by Al-Kindi Centre for Research and Development, London, United Kingdom. 
Considering the uniqueness of the situation, identification of the sources of stress for e-learners and their emotional struggles in online education platforms is of great value. Such knowledge can delineate students' challenges and needs in the conduct of webbased teaching and pave the ground for targeted interventions addressing students' emotional and mental needs. Identifying the stressors for students can also contribute to online instruction success and improved learning outcomes since research shows that negative and inaccurate perceptions can result in attrition, and low motivation and persistence (Muilenburg \& Berge 2005). Additionally, such an understanding aids the educational institutions to arm the students with the necessary strategies in the case of the new waves or the spread of similar diseases. Finally, such an analysis adds to our understanding of the social context of online learning.

\section{Review of Literature}

Prior research on students' perceptions about online instruction has demonstrated that students may choose it because of flexibility, convenience, cost-effectiveness, accountability, and compatibility with other life activities (Chen, et al., 2019; Ruiz, Mintzer, \& Leipzig, 2006). However, the experience of ERT under the outbreak of the Covid-19 is unique, considering the lack of preparation and willingness of the majority of the individuals taking it (Chahkandi, 2021). Remote teaching under the conditions of the pandemic has also been featured by internet connectivity issues, hardware or software problems, low motivation and course satisfaction, and fitting the course in with family/home obligations and work schedule (Means \& Neisler, 2021). Additionally, socioeconomic and cultural barriers along with limited access to technological resources have been shown to restrict individuals' access to virtual learning (Baticulon et al., 2021). As such, it is believed to exacerbate the preexisting educational and social inequities including accessibility to devices and the digital divide (Shin \& Hickey, 2020).

The compulsory transition to online modality and the resultant challenges such as moving off campus unexpectedly, the loss of in-person lectures and laboratories, lack of personal interactions, and overall decreased learning capability have been the sources of excessive fear, anxiety, and negative perceptions among students (Cardenas, Bustos, \& Chakraborty, 2020; Unger \& Meiran, 2020). Along this line, Baticulon et., al. (2021) reported students expressing feelings of anxiety, burnout, loneliness, homesickness, grief, and hopelessness. They were also found to have worries regarding performance in online examinations, their plans, and academic life, possible delays in training, and the safety of their families against COVID-19 (Baticulon et., al. 2021; Clabaugh, Duque \& Fields, 2021; Wang, Liu, Zhang, Xie, Yang, 2021). Congruent with these findings, Yate, Starkey, Egerton, and Flueggen (2020) noted that only a small number of students had a preference for online collaboration. They valued proximity with others, accessibility of peers and teachers as well as the immediacy of support offered by face-to-face collaboration. These findings point to the high-risk levels of academic stress and students' poor emotional well-being. They indicate that students' psychological needs should be addressed immediately through socio-emotional and psychological support (Shin \& Hickey, 2020).

Despite the unpreceded conditions of online education in the time of the Covid-19 crisis, little attention has been given to the emotional dimensions of ERT and our understanding of students' emotional experiences is still limited (Johnson, Veletsianos, \& Seaman 2020; Naji et al., 2020). In particular, determinants of stress for EFL students in virtual learning have been poorly addressed in the literature. This study aims to fill this gap by addressing the following research question: What are the antecedents of stress for EFL students in the emergency remote teaching context?

\subsection{Theoretical Framework}

This study is informed by the notion of the genealogy of emotions (Zembylas, 2002; 2005). It focuses on how emotions are shaped and altered as a result of learners' interaction with particular events, objects, and persons. In effect, it considers how learners' emotional experiences are influenced in connection to self (individual reality), others (social interactions), and educational policy and culture (sociopolitical context) (Zembylas, 2001). Furthermore, it analyses the historicity of emotions as well as the origins and antecedents giving rise to those emotions. This study aims to analyze EFL learners' experience of stress in the context of online learning and the factors contributing to that stress.

\section{Methodology}

\subsection{Setting and Participants}

This study was carried out at a state university during the academic year 2020-2021 and volunteered students were recruited for this study. The participants were 68 undergraduate students in English Literature and Translation Studies (41 females and 27 Males). The average age of the participants was 26.5, with their ages ranging from 18 to 35 . The participant students were being taught synchronously in the online platform of the learning management system (LMS) and the classes were delivered in Adobe Connect. Of these participants, 17 students volunteered to undergo semi-structured interviews. 


\subsection{Instrument}

Two instruments were utilized for this study:

\subsubsection{Emotion Diary}

Considering that interviewing data can be subject to memory bias (Grandey, Tam, \& Brauburger, 2002), diary data were utilized to compensate for the loss and to allow for exploration of emotions according to their genealogy and historicity. The online diary was adapted from Averill (1982), Oatley and Duncan (1992), and Zembylas (2002) and was developed in three questions. Question 1 required participants' demographic information, including age and sex. The second question listed 21 emotions from among which respondents were required to identify the one(s) they experienced during the scenario. The list of emotions was adapted from Pekrun, Goetz, Titz, and Perry (2002) with some modifications being made during the pilot testing of the questionnaire. These emotions include joy, enthusiasm, satisfaction, pride, love and affection, intimacy, relief, empathy, enjoyment, comfort, disappointment, disgust, guilt, boredom, anger, stress and anxiety, surprise, fear, sorrow, sadness, and powerlessness. Following, participants reflected on the incident (what happened?) and antecedents of emotion (what made you feel this way?) in an openended format. For the purpose of this study, only those diaries which reported experiencing stress and anxiety were taken into consideration. Together, a corpus of 453 diary entries was compiled from e-learners from among which 187 diaries reported students' experiencing stress. The emotion diary is presented in Appendix A.

\subsubsection{Interview}

The interview protocol was developed based on prior studies on emotions (Hosotani \& Imai-Matsumura, 2011; Sutton, 2004; Yin \& Lee, 2012), along with questions emerging from students' emotion diaries. Volunteered respondents were asked to reflect on emotional episodes provoking stress and anxiety in the online courses and report the critical "emotional incidents" (Erb, 2002) or "significant emotional episodes" (Hargreaves, 2000) which were emotionally salient. The interviews lasted for about 15 minutes and were conducted in Persian at the end of the semester to probe more details on the emergent themes developed through analysis of diaries and establish saturability of analysis. The interview data were coded and transcribed for analysis. A list of interview questions is provided in Appendix B.

\subsection{Procedure}

At the commence of the academic year, the purpose of the research was explained to online students and volunteered students were recruited for the study. Then, the translated and pilot-tested questionnaire was shared with them and they were asked to record every event describing their emotions as well as their experience of online learning for the whole academic semester. The number of sheets was not specified and they were allowed to submit as many papers as they wished related to every online course they had to minimize the effects particular professors or courses might have on students' emotions. Students were asked to submit their diaries electronically and immediately after the class to avoid memory loss. Further, reminders were also given to students at the beginning of every week to help the completion of the diaries. Students received credits for the completed diaries at the end of the semester.

\subsection{Data Analysis}

The data obtained from interviews and diary entries were subjected to content analysis using similar procedures. First, all the diary journals and interview transcripts were read and summarized to help the researcher familiarize herself with the data and simultaneously analytic memo writing was utilized to help the researcher record her thoughts and reflections during the coding process (Bogdan \& Biklen, 2007). Next, the incidents were coded manually and analyzed inductively for the major themes and categories of the antecedents of stress they represented. To do so, Braun and Clarke's (2006) thematic analysis method was drawn on. This phase of the coding was performed by two researchers working separately to enhance the trustworthiness of the study. Once the categories were created, they compared the categories and negotiated the discrepancies until agreed-upon themes were reached (Kvale, 1996). Further re-readings were done to ensure that all pieces of data had been incorporated into the analysis. The emergent themes were then quantified by tallying the number of instances of each theme in the corpus. Finally, segments of verbatim quotes were selected to illustrate the emergent themes.

\section{Results}

The major stressors that emerged from the analysis of the diaries were classified into academic-related stressors, psychological stressors, technical-related stressors, and life-related stressors, respectively. Stressors within each theme were further coded into subcategories presented in Table 1. A detailed account of each category is discussed below. (Note that F=female; $M=$ male, $I=$ interview; $\mathrm{D}=$ diary). 
Table 1: Stressors in Online Learning Context

\begin{tabular}{|c|c|c|c|}
\hline \multirow[t]{2}{*}{ Stressors } & \multicolumn{2}{|c|}{$\begin{array}{l}\text { Accounts } \\
\text { reported (N) }\end{array}$} & \multirow[t]{2}{*}{ Subcategories } \\
\hline & $\mathbf{I}$ & D & \\
\hline Academic-related & 22 & 108 & $\begin{array}{l}\text { online exams and grades, students' English competency, } \\
\text { instructional demands and workload, and teaching quality. }\end{array}$ \\
\hline Psychological related & 15 & 41 & $\begin{array}{l}\text { low self-concept and efficacy beliefs, students' comparing } \\
\text { themselves to others, adapting learning styles, and social } \\
\text { interactions and expectations. }\end{array}$ \\
\hline Life-related & 17 & 34 & $\begin{array}{l}\text { concerns about their future life, work-life balance, health and } \\
\text { safety, and distractions and multitasking. }\end{array}$ \\
\hline Technical-related & 11 & 18 & Technical failing and low technological competence \\
\hline
\end{tabular}

\subsection{Academic-related Stressors}

The most frequent determinants of stress that EFL students subscribed to in remote learning concerned academic-related ones. This category accounted for $58 \%$ of all the diaries pertained exams and grades, students' limited English competency, teaching quality, and instructional demands, and heavy workload.

\subsubsection{Exams and Grades}

In regards to exams, students experienced stress mainly in relation to grades, intense exam schedules without study time, backto-back exams in one day, lengthy and detailed questions with limited time to answer, and lack of timely and effective feedback. More importantly, the conditions under which online exams were administered were the most frequently mentioned determinant of stress among students. For instance, aiming to prohibit students from cheating, online exams were usually conducted within a limited time frame:

In paper-and-pencil exams, I normally review the questions and the answers before I hand over my final paper.... When I heard about the exam time and the lack of access to previous questions, my mind went blank. I totally lost my concentration. .... I either didn't read the questions carefully, or I didn't get them right as I was too stressed. (M, D. 240)

Besides time restrictions, other online exam settings contributing to increasing levels of stress included not having the opportunity to review the questions and the answers, lack of access to the previous questions, changing the order of the questions and the choices, and presenting each question in a separate page, internet connectivity problems and low speed to navigate among the pages, not being able to submit the answers, and low typing speed.

\subsubsection{English Competency}

The majority of the participants expressed worries and concerns about their inadequate English proficiency and confidence in using English. As the major cause of linguistic inadequacy, students referred to inefficient instruction in schools and limited exposure to English before they attended university. As such, they reported feeling incompetent with respect to almost all aspects of the English language including oral proficiency, listening comprehension, vocabulary knowledge, grammatical competence, reading and writing skills, and pronunciation.

The professor asked us to summarize an audio file each week and email it to him. I had a very negative feeling. I was all filled with helplessness and frustration because the audio files seemed so tough to me. ... the deadlines put extra pressure on me. I had to start somewhere, but I had so much on my plate that rarely did I find time to work on the files the way I should have. (M, I. 11)

The poor English proficiency coupled with fear of making mistakes and being laughed at were considered as significant hindrances in volunteering and participating in-class activities, which itself gave way to lower scores. More specifically, they were recognized as deteriorating quality teacher-student relationships considering that students were not able to establish connections in English and were obliged to keep silent in class. By the same token, inadequate English competence was believed to result in students' 
problems with understanding the concepts to be remained unresolved since they did not venture to ask for clarifications and raise their questions.

"When grammar is taught all in English, I can't make sense of its many parts. I can't ask my questions either in online classes.... (F, D. 289)

The lack of required proficiency in English and poor performance on exams were also linked to others' appraisals of students and were considered as threats to one's face and self-concept. That is to say, students expressed feeling stressed not only in relation to their academic performance but also regarding the loss of social status and the damage to one's self-image. "The professor passed the microphone to me to answer the question, but I couldn't. This made me feel ashamed and too stressed as I knew that not only did I lose score, but also others' view toward me would change." (F, D. 6)

\subsubsection{Instructional Demands and Excessive Workload}

Almost all students acknowledged experiencing significant stress in relation to heavy workload, intense schedules, and timetables, overshadowing some lessons by heavy course loads of others, and falling off track in some courses. Having the classes started 2 months later due to the Corona lockdown, successive classes with makeup sessions each day, large quantities of deliverable assignments, the complexity of teaching content and students' low understanding of the lessons, as well as regular classroom presentations and evaluations due within a short time impeded students from keeping up with the course demands and requirements and created serious challenges in time and workload management.

Intense classes and make-up sessions made us feel pressured as we had to have twice as many as our routine classes for each course per week. The heavy course load and large amounts of writing we did for the 'listening and speaking course' left us with no time for the other courses. We had no time to study and plan for the finals and the exams were all coming up one after another with no interval. $(M, I .14)$

\subsubsection{Instructional Quality}

Much of the stress students were struggling with stemmed from teaching without consideration of and connections with students' prior knowledge and their current competence, monotonous and lecture-based instruction without regular check-ins, teachers' being camera shy and not showing up their faces, failing to provide ample opportunities for students to interact with each other as well as with course material, and neglecting to gauge students' comprehension of the course content and goals.

In the very first session, the professor started teaching and explaining everything in English. He even didn't use a word of Persian to congratulate the new academic year, nor a word to introduce the book and his teaching method. ... I was all panicked. I was thinking I wouldn't be able to get the hang of it. It all turned out to be so tough from the beginning. (M, D. 36)

\subsection{Psychological Stressors}

The second most salient stressor for EFL students which was reflected in $22 \%$ of the diary entries involved psychological barriers. Issues such as low self-esteem and efficacy beliefs, students' comparing themselves to others, adapting learning styles, lack of access to teachers and peers, and the newness of the online learning environment were the major psychologically-related antecedents expressed by EFL online learners.

\subsubsection{Low Self-efficacy and Self-concept}

Some online learners were signaled to lack essential self-efficacy and self-confidence for engaging in internet-based learning. "I feel incapable of doing things and I always blame myself for not being as competent as others. ... It's a shame I can't understand and speak fluently like others in the class." (F, D. 189). The main instantiations of stress in this category were attributed to students' lack of self-esteem to speak in public and their low self-image. Regarding reasons, students noted inadequate English competency and an incomplete comprehension of the lessons. "I feel intimidated when I see my classmates answer the professor's questions so quickly while I get almost nothing. ... I'm not good at English because I have never taken any English courses." (F. D. 130). Some stated that they were afraid of creating negative impressions in others and feared making mistakes. "Despite my efforts, I can't participate in class. I study before the class and I know the answer, but I don't dare to speak my mind. ... This happens mostly because of low confidence." (F, D. 194).

\subsubsection{Students' Comparing Themselves to Others}

The English classroom as a milieu for the realization of different levels of English competencies and being associated with the reward and evaluation system provide a ground for students to compare themselves to others. In effect, students were frequently confronted with peers having a remarkable background of English and learning experience in language institutes, while for some, the university classes were the first serious encounters with the English language. In such an assessment-oriented culture, social comparisons were inevitable, and hence, it emerged as a significant determinant of stress. 
I'm lagging behind others. I can't be successful in this major and I see no bright future ahead of me. I'm always comparing myself to others and I realize that I won't be able to pass the courses with ease. $(F, I .4)$.

\subsubsection{Adapting Learning Styles}

Having experienced learning in physical classes with the teacher's feedback readily available to them, sharing social ties, doing hands-on practices, and taking advantage of peer collaboration, some students found it stressful to accommodate to remote education. Online classes were primarily based on a one-way transfer of information and lectures, and students expressed difficulty understanding the live classes and staying focused on the screen for long periods especially when the teacher's face was not accessible. For these students, personal contact with teachers and peers was key to successful learning.

As we are taught remotely, I'm always worried about not learning the lessons. I'm also always on my toes in case the Internet is disconnected and I miss part of the class.... For me, I have to listen to and see the professor in person in order to learn, and adapting virtually is such a big deal. (F, D. 13)

Furthermore, studying remotely necessitates a high degree of self-discipline, self-control, and motivation. It requires students to exert greater agency and autonomy for their learning and possess higher degrees of time management skills in order to adjust themselves to the pace of the course. "Online education makes students somehow laid back and because many of them rely on cheating, they may not pay due attention to the course and homework, or because the class archives are available, they may not take the classes seriously." (M, I. 10).

\subsubsection{Social Interactions and Expectations}

The hallmark of quality teaching is working teacher-student relationships and interactions. However, the online learning environment is mainly featured by poor communication, limitations in nonverbal communication, constraints in emotional connection, and lack of immediate feedback. In these conditions of impersonal teaching, students expected their professors to cultivate a sense of community to enhance student learning and to perceive their situation and their struggles to cope with the high demands of academic life. Considering that the first-year students were admitted to university 2 months after the beginning of the academic year, they missed some of the general courses held jointly with the non-entry students. When they expressed their concerns about the missed classes to their professor, they were replied to watch the class archives as no review would be done for them. One student illustrated her feelings along these lines "We felt we were not perceived by the professor. We expected him to understand our situation..., but he didn't and the instructor's behavior offended us even more." $(F, I .8)$

\subsection{Life-related Stressors}

Life-related stressors included concerns about future life, work-life balance, multi-tasking and distractions, and health and safety issues.

\subsubsection{Concerns about Future Life}

Stressors pertaining to the future life domain mainly concern future goals, occupation, and education. The problems prevalent in the society due to global pandemic and in particular, economic crisis concerned some students as well. "My future and the presence of economic and health problems in the society have had me worried. ...I'm concerned about the effect of all these negative vibes. They are always with me." (F, D. 62). For male participants approaching graduation, the pressure associated with military service constituted a main cause of stress as well (M, D. 222). Some of the participants, particularly those who lacked adequate mastery of language, expressed doubts regarding their choice of the academic major and reported the probability of dropping out and leaving the university.

Since the beginning of the class, I have always been feeling worried, stressed, and despaired because I can't figure out what the professor and the other students are saying. ... because of my limited knowledge, I think I won't be able to continue with this major. I'm thinking of dropping out and leaving university altogether. (M. I.15).

\subsubsection{Work-life Balance}

Distant learning allows different obligations and responsibilities to be combined and overlapped simultaneously. Accordingly, it is common for students to experience pressure and strain fitting their learning time in with the family or work commitments. "I was so tired and I was listening to the professor almost half-sleep. Because I work, I feel I'm fed up. I have had enough" (M, D. 125). One of them noted the absence of active participation in class as a sign of disrespect for the professor and worried that it would harm the quality of teacher-student relationships.

I was attending the class at my workplace. I had to both follow the class and manage my responsibilities at work. I was worried that the professor would take offense and would think that because the class was virtual I was headless." (F, D. 398). 


\subsubsection{Health and Safety}

Being locked down in the pandemic era, many students expressed loneliness, isolation, and helplessness. They also expressed great concern and worry over the health of their family members. One described living far from her family for over 2 weeks since her family was being locked in quarantine (F, D. 58). A second student explained how she suffered from the loss of one of the family members who were quite young with 2 small children as a result of Corona disease ( $F, d$. 104). Still, a further student shared great concerns over the situation amid the Covid-19 outbreak and longed to turn back to university campus "I hope the disease goes away soon and we can get back to university. I miss my classes and university." (F, I. 2)

\subsubsection{Multitasking and Distractions}

Distractors and multi-tasking were identified to generate great strain for students while in class. Examples include having guests at home, kids interrupting the live classes, and receiving phone calls and doorbells. By and large, it was challenging for students to find an appropriate space for the class while at home. "When I'm in class speaking, I'm just worried about my little brother's entering the room or someone's calling me out. ... generally, because I can't find a quiet place, it stresses me out." (F, I. 12). Students also described instances of being involved in household chores, parents' calls for helping out around the house, and running errands. "We had a company that night and during the grammar class I was all tied up with the party's preparations... I understood absolutely nothing from the class." (F, D. 148).

\subsection{Technical Issues}

Participant students identified technical components of the online classes as a considerable cause of stress. The major stumbling blocks and stressors were reported to be internet coverage and connectivity problems, logging on, and accessing classroom links, interrupting voice, crashing devices and systems, overloaded platforms, problems with streaming software and other digital tools, sharing gadgets, and network overload during the high usage rate periods. Besides technical faults, students' technological skills and computer literacy were identified to be extra sources of stress when a problematic scenario occurred.

I made every effort to prepare my PowerPoint slides. I added some background music to the slides and recorded my voice on them, too. But the music was too loud and my voice could be barely heard. ... I didn't enjoy the Yalda night as I was up till 3:00 a.m. working on my presentation.... But it didn't turn out as I expected. I was too bad. I'm stressed stressed, stressed." $(F, D .142)$.

\section{Discussion}

The current study aimed to explore the main antecedents of stress for EFL students in online university classes. Analysis of the data gleaned from diary entries and interview transcripts pointed to four areas of stress for online learners: academic-related stressors, psychological issues, life-related issues, technical problems, and students' technological skills. These results confirm the previous studies on students' perception of stress in face-to-face settings. (Acharya, Jin, \& Collins, 2018; Bulo, \& Sanchez, 2014; Lee \& Jang, 2015; Molodynski, et al., 2021). The results also echo the literature on the perceived sources of stress in the light of the Covid-19 (Lin, et. al., 2020; Wang, et. al., 2021).

In addition to the stressors experienced in face-to-face contexts, this study pointed out that students in the web-based learning environment are exposed to unique and extra sources of stress stemming from the digital nature of the online classes. These stressors concern students' technological competence along with the hassles in communicating with peers and teachers. It was evidenced that, in addition to content knowledge, successful performance in online education demands having the basic technological competence and the availability of the essential infrastructure including reliable internet access. Therefore, a broader definition of proficiency is required to cover the skills expected of students in online learning.

A number of studies have proposed the components of effective online learning. Garrison (2009), for example, offered the Community of Inquiry model encompassing teaching, social, and cognitive dimensions. In a similar vein, Kauffman (2015) outlined the main learner characteristics and skills contributing to student success in and satisfaction with online learning including higher levels of emotional intelligence, self-regulatory skills, reflective/visual learning styles, and internal locus of control. While these models seek to capture the complexity of online learning, they fail to consider the technological prerequisites for the successful completion of online learning. This dimension is of great importance considering that computer self-efficacy has been shown as a significant predictor of emotional and cognitive engagement in online settings (Pellas, 2014).

Previous literature also characterizes lack of direct contact and social isolation as one of the major barriers to online learning (Bulo, \& Sanchez, 2014; Chahkandi, 2021; Olasina, 2019). In the light of these findings, it seems plausible that the possibility for interaction, particularly with professors, has been figured out as one of the main motivations behind students' preference for on-campus instruction (Tichavsky, Hunt, Driscoll, \& Jicha., 2015). These findings achieved as a result of the exploratory nature of this study are significant in that studies applying the scales developed for face-to-face contexts (e.g. Wang, et. al., 2021) fail to subscribe to these 
causes of stress in digital learning. As such, the categories identified in this study can be employed for developing tailor-made scales applicable to online education in future research.

Online students in this study were reported to lack self-efficacy and self-concept in regard to academic tasks and in particular, course load and time management. Similar findings are found in other studies where students have been reported to suffer from declining motivation, self-efficacy, cognitive engagement, and self-discipline as a consequence of the sudden transition to distance education during the pandemic (Aguilera-Hermida, 2020; Baticulon, et. al., 2021). Self-efficacy beliefs are directly related to resilience, persistence, and successful completion of learning (Alghamdi, Karpinski, Lepp, \& Barkley 2020; Cho and Shen, 2013). Accordingly, educators must take into account learners' motivations, needs, and past experiences in their endeavors to engage students in virtual learning (Chen, et. al., 2019). Further, self-regulated learning strategies such as time management, selfmonitoring, and effort regulation, along with harnessing students' technological skills should be incorporated as part of explicit instructional goals and practices of online courses.

\section{Conclusion}

The key focus of this study was to identify the sources of stress associated with the online learning environment for EFL undergraduate students. It attempted to add to our understanding of the features of e-learning contexts and the barriers to the successful implementation of online education. Empirically, the study has implications for teachers and instructors as it implies how quality online instruction can be offered by improving teaching quality, explicit teaching of self-regulatory and stress management strategies (e.g. in relation to exam-related stressors), and providing for a pedagogy of care (Bozkurt \& Sharma, 2020). Additionally, dynamic assessment methods can be utilized to not only improve students' proficiency but also foster positive perceptions towards assessment (Ebadi \& Rahimi, 2019). Therefore, future research strands can delve into how a change in assessment practices can affect e-learners' perceived level of stress. While informative, the results of this study should be interpreted with care. The sample of this study mainly consists of female participants and previous literature reveals that females generally perceive higher levels of stress than their male counterparts (Wang, et. al., 2021). Furthermore, the stress experienced by the participants can be subject to Iranian socio-cultural norms and socialization process given that culture influences the frequency and intensity of emotions (Boiger, Mesquita, Uchida, \& Barrett, 2011) as well as the appraisal of situations in which the emotions are elicited (De Leersnyder, Boiger, \& Mesquita, 2013). Finally, students' perceived level of stress can be influenced by individual variables including personality differences, age, proficiency level, and motivation towards language learning (Ohata, 2005).

\section{References}

[1] Acharya, L., Jin, L., \& Collins, W. (2018). College life is stressful today-Emerging stressors and depressive symptoms in college students. Journal of American college health, 66(7), 655-664. https://doi.org/10.1080/07448481.2018.1451869

[2] Aguilera-Hermida, A. P. (2020). College students' use and acceptance of emergency online learning due to COVID-19. International Journal of Educational Research Open, 1, 100011. https://doi.org/10.1016/j.jedro.2020.100011

[3] Alghamdi, A., Karpinski, A. C., Lepp, A., \& Barkley, J. (2020). Online and face-to-face classroom multitasking and academic performance: Moderated mediation with self-efficacy for self-regulated learning and gender. Computers in Human Behavior, 102, $214-222$. https://doi.org/10.1016/j.chb.2019.08.018

[4] Amzalag, M., Shapira, N., \& Dolev, N. (2021). Two Sides of the Coin: Lack of Academic Integrity in Exams During the Corona Pandemic, Students' and Lecturers' Perceptions. Journal of Academic Ethics, 1-21. https://doi.org/10.1007/s10805-021-09413-5

[5] Averill, J. (1982). Anger and aggression: An essay on emotion. Springer: New York.

[6] Baticulon, R.E., Sy, J.J., Alberto, N.R.I. et al. Barriers to Online Learning in the Time of COVID-19: A National Survey of Medical Students in the Philippines. Med.Sci.Educ. 31, 615-626 (2021). https://doi.org/10.1007/s40670-021-01231-z

[7] Bogdan, R. C., \& Biklen, S. K. (2007). Qualitative research for education: An introduction to theories and methods. New York: Pearson Education, Inc.

[8] Boiger, M., Mesquita, B., Uchida, Y., \& Barrett, L. F. (2011). The situational construction of anger and shame in three cultures. In B. Mesquita \& M. Boiger (Chairs), The social construction of emotion. Symposium conducted at the plenary meeting of the International Society for Research on Emotion (ISRE), Kyoto, Japan.

[9] Bozkurt, A., \& Sharma, R. C. (2020). Emergency remote teaching in a time of global crisis due to CoronaVirus pandemic. Asian Journal of Distance Education, 15(1), i-vi. http://www.asianjde.com/ojs/index.php/AsianJDE/article/view/447

[10] Braun, V., \& Clarke, V. (2006). Using thematic analysis in psychology. Qualitative research in psychology, 3(2), $77-101$.

[11] Bulo, J. G., \& Sanchez, M. G. (2014). Sources of stress among college students. CVCITC Research Journal, 1(1), 16-25.

[12] Cardenas, M. C., Bustos, S. S., \& Chakraborty, R. (2020). A 'parallel pandemic': The psychosocial burden of COVID-19 in children and adolescents. Acta Paediatrica (Oslo, Norway: 1992).

[13] Chahkandi, F. (2021). Online Pandemic: Challenges of EFL Faculty in the Design and Implementation of Online Teaching Amid the Covid-19 Outbreak. Foreign Language Research Journal, 10(4), 706-721. https://dx.doi.org/10.22059/jflr.2021.313652.774

[14] Chen, B. Y., Kern, D. E., Kearns, R. M., Thomas, P. A., Hughes, M. T., \& Tackett, S. (2019). From modules to MOOCs: application of the six-step approach to online curriculum development for medical education. Academic Medicine, 94(5), 678-685. DOI: 10.1097/ACM.0000000000002580

[15] Cho, M. H., \& Shen, D. (2013). Self-regulation in online learning. Distance education, 34(3), 290-301.

https://doi.org/10.1080/01587919.2013.835770 
[16] Clabaugh, A., Duque, J. F., \& Fields, L. J. (2021). Academic stress and emotional well-being in united states college students following the onset of the COVID-19 pandemic. Frontiers in Psychology, 12. https://dx.doi.org/10.3389\%2Ffpsyg.2021.628787

[17] De Leersnyder, J., Boiger, M., \& Mesquita, B. (2013). Cultural regulation of emotion: Individual, relational, and structural sources. Frontiers in psychology, 4, 55.

[18] Ebadi, S., \& Rahimi, M. (2019). Mediating EFL learners' academic writing skills in online dynamic assessment using Google Docs. Computer Assisted Language Learning, 32(5-6), 527-555. https://doi.org/10.1080/09588221.2018.1527362

[19] Erb, C. S. (2002). The emotional whirlpool of beginning teachers' work. Paper presented at the annual meeting of the Canadian Society of Studies in Education, Toronto, Canada.

[20] Garrison, D. R. (2009). Communities of inquiry in online learning. In Encyclopedia of distance learning, Second edition (pp. 352-355). IGI Global. 10.4018/978-1-60566-198-8.ch052

[21] Grandey, A. A., Tam, A. P., \& Brauburger, A. L. (2002). Affective states and traits in the workplace: Diary and survey data from young workers. Motivation and Emotion, 26(1), 31-55. https://doi.org/10.1023/A:1015142124306

[22] Hargreaves, A. (2000). Mixed emotions: Teachers' perceptions of their interactions with students. Teaching and teacher education, 16(8), 811826. https://doi.org/10.1016/S0742-051X(00)00028-7

[23] Hodges, C., Moore, S., Lockee, B., Trust, T., \& Bond, A. (2020). The difference between emergency remote teaching and online learning. Educause Review, ( March 27, 2020). https://er.educause.edu/articles/2020/3/the-differencebetween-emergency-remote-teaching-andonline-learning.

[24] Hosotani, R., \& Imai-Matsumura, K. (2011). Emotional experience, expression, and regulation of high-qua ty Japanese elementary school teachers. Teaching and Teacher Education, 27(6), 1039-1048. Hosotani, R., \& Imai-Matsumura, K. (2011). Emotional experience, expression, and regulation of

[25] Johnson, N., Veletsianos, G., \& Seaman, J. (2020). US Faculty and Administrators' Experiences and Approaches in the Early Weeks of the COVID-19 Pandemic. Online Learning, 24(2), 6-21.

[26] Kauffman, H. (2015). A review of predictive factors of student success in and satisfaction with online learning. Research in Learning Technology, 23. http://repository.alt.ac.uk/id/eprint/2415

[27] Kvale, S. (1996). The 1,000-page question. Qualitative inquiry, 2(3), 275-284. https://doi.org/10.1177\%2F107780049600200302

[28] Lederer, A. M., Hoban, M. T., Lipson, S. K., Zhou, S., \& Eisenberg, D. (2021). More than inconvenienced: the unique needs of US college students during the CoViD-19 pandemic. Health Education \& Behavior, 48(1), 14-19. https://doi.org/10.1177\%2F1090198120969372

[29] Lee, J., \& Jang, S. (2015). An exploration of stress and satisfaction in college students. Services Marketing Quarterly, 36(3), $245-260$. https://doi.org/10.1080/15332969.2015.1046774

[30] Lin, X. J., Zhang, C. Y., Yang, S., Hsu, M. L., Cheng, H., Chen, J., \& Yu, H. (2020). Stress and its association with academic performance among dental undergraduate students in Fujian, China: a cross-sectional online questionnaire survey. BMC medical education, 20, 1-9. https://doi.org/10.1186/s12909-020-02095-4

[31] Means, B., \& Neisler, J. (2021). Teaching and Learning in the Time of COVID: The Student Perspective. Online Learning, $25(1), 8-27$.

[32] Molodynski, A., Lewis, T., Kadhum, M., Farrell, S. M., Lemtiri Chelieh, M., Falcão De Almeida, T., ... \& Bhugra, D. (2021). Cultural variations in wellbeing, burnout, and substance use amongst medical students in twelve countries. International Review of Psychiatry, 33(1-2), 37-42. https://doi.org/10.1080/09540261.2020.1738064

[33] Muilenburg, L. Y., \& Berge, Z. L. (2005). Student barriers to online learning: A factor analytic study. Distance education, 26(1), 29-48. https://doi.org/10.1080/01587910500081269

[34] Naji, K. K., Du, X., Tarlochan, F., Ebead, U., Hasan, M. A., \& Al-Ali, A. K. (2020). Engineering Students' Readiness to Transition to Emergency Online Learning in Response to COVID-19: Case of Qatar. EURASIA Journal of Mathematics, Science and Technology Education, 16(10).

[35] Oatley, K., \& Duncan, E. (1992). Incidents of emotion in daily life. In K. T. Strongman (Ed.), International Review of Studies on Emotion (Vol. 2, pp. 250-293). Chichester, UK: Wiley.

[36] Ohata, K. (2005). Potential sources of anxiety for Japanese learners of English: Preliminary case interviews with five Japanese college students in the US. TESL-EJ, 9(3), n3.

[37] Olasina, G. (2019). Human and social factors affecting the decision of students to accept e-learning. Interactive Learning Environments, 27(3), 363-376. https://doi.org/10.1080/10494820.2018.1474233

[38] Pekrun, R., Goetz, T., Titz, W., \& Perry, R. P. (2002). Academic emotions in students' self-regulated learning and achievement: A program of qualitative and quantitative research. Educational psychologist, 37(2), 91-105. https://doi.org/10.1207/S15326985EP3702_4

[39] Pellas, N. (2014). The influence of computer self-efficacy, metacognitive self-regulation, and self-esteem on student engagement in online learning programs: Evidence from the virtual world of Second Life. Computers in Human Behavior, 35, 157-170. https://doi.org/10.1016/j.chb.2014.02.048

[40] Raza, S. A., Qazi, W., Khan, K. A., \& Salam, J. (2021). Social isolation and acceptance of the learning management system (LMS) in the time of COVID-19 pandemic: an expansion of the UTAUT model. Journal of Educational Computing Research, 59(2), 183-208. https://doi.org/10.1177\%2F0735633120960421

[41] Ruiz, J. G., Mintzer, M. J., \& Leipzig, R. M. (2006). The impact of e-learning in medical education. Academic medicine, 81(3), $207-212$.

[42] Shin, M., \& Hickey, K. (2020). Needs a little TLC: Examining college students' emergency remote teaching and learning experiences during COVID-19. Journal of Further and Higher Education, 1-14. https://doi.org/10.1080/0309877X.2020.1847261

[43] Sutton, R. E. (2004). Emotional regulation goals and strategies of teachers. Social Psychology of Education, 7(4), 379-398. https://doi.org/10.1007/s11218-004-4229-y

[44] Tichavsky, L. P., Hunt, A. N., Driscoll, A., \& Jicha, K. (2015). It's Just Nice Having a Real Teacher": Student Perceptions of Online versus Faceto-Face Instruction. International Journal for the Scholarship of Teaching and Learning, 9(2), n2.

[45] Unger, S., \& Meiran, W. R. (2020). Student Attitudes towards Online Education during the COVID-19 Viral Outbreak of 2020: Distance Learning in a Time of Social Distance. International Journal of Technology in Education and Science, 4(4), 256-266. 
[46] Wang, J., Liu, W., Zhang, Y., Xie, S., \& Yang, B. (2021). Perceived Stress Among Chinese Medical Students Engaging in Online Learning in Light of COVID-19. Psychology Research and Behavior Management, 14, 549. https://dx.doi.org/10.2147\%2FPRBM.S308497

[47] Yates, A., Starkey, L., Egerton, B., \& Flueggen, F. (2020). High school students' experience of online learning during Covid-19: the influence of technology and pedagogy. Technology, Pedagogy, and Education, 1-15. https://doi.org/10.1080/1475939X.2020.1854337

[48] Yin, H. B., \& Lee, J. C. K. (2012). Be passionate, but be rational as well: Emotional rules for Chinese teachers' work. Teaching and Teacher Education, 28(1), 56-65. https://doi.org/10.1016/j.tate.2011.08.005

[49] Zembylas, M. (2001). Chapter 5: A Paralogical Affirmation of Emotion's Discourse in Science Teaching. Counterpoints, $150,99-128$. https://www.jstor.org/stable/42976484

[50] Zembylas, M. (2002). Constructing genealogies of teachers' emotions in science teaching. Journal of Research in Science Teaching: The Official Journal of the National Association for Research in Science Teaching, 39(1), 79-103. https://doi.org/10.1002/tea.10010

[51] Zembylas, M. (2005). Discursive practices, genealogies, and emotional rules: A poststructuralist view on emotion and identity in teaching Teaching and teacher education, 21(8), 935-948. https://doi.org/10.1016/j.tate.2005.06.005

\section{Appendix A \\ Emotion Diary}

Gender:...

Age:.

Which of the following emotions you experienced (you might have experienced more than one)?

$\begin{array}{lll}\text { Joy } \square & \text { enthusiasm } \square & \text { intimacy } \square \\ \text { satisfaction } \square & \text { pride } \square & \text { love and affection } \square \\ \text { relief } \square & \text { empathy } \square & \text { enjoyment } \square \\ \text { comfort } \square & \text { disgust } \square & \text { guilt } \square \\ \text { boredom } \square & \text { anger } \square & \text { stress and anxiety } \square \\ \text { surprise } \square & \text { fear } \square & \text { powerlessness } \square \\ \text { sorrow } \square & \text { sadness } \square & \text { disappointment } \square\end{array}$

1. What were you doing and what happened when you experienced that emotion?

2. Why did you experience that emotion? What were you thinking about at that time?

3. How did you treat the emotion?

\section{Appendix B}

Interview questions were used to probe EFL students' perception of the stressors in ERT.

1. What stresses you out in online classes? Why?

2. What unique sources of stress have you experienced in online classes?

3. What critical incident can you remember when you felt stressed in online classes?

4. What qualities of the teacher stress you out in online learning?

5. What are your own features which lead to stress in online classes?

6. What sources of stress are due to the Covid-19 pandemic? 